\title{
Reproducibility of Skin Temperature Response after Cold Stress Test Using the Game Ready System: Preliminary Study
}

\author{
Jose Ignacio Priego-Quesada $1,2, * \mathbb{1}$, Alexis Gandia-Soriano ${ }^{2}$, Maria Teresa Pellicer-Chenoll ${ }^{3}$, \\ Ignacio Catalá-Vilaplana ${ }^{1}{ }^{\circledR}$, Jose Luis Bermejo-Ruiz ${ }^{3}$, Alberto Encarnación-Martínez ${ }^{1} \mathbb{1}$, \\ Rosario Salvador-Palmer ${ }^{2} \mathbb{D}$ and Rosa Cibrián Ortiz de Anda ${ }^{2} \mathbb{D}$
}

check for updates

Citation: Priego-Quesada, J.I. Gandia-Soriano, A.; Pellicer-Chenoll, M.T.; Catalá-Vilaplana, I.; BermejoRuiz, J.L.; Encarnación-Martínez, A.; Salvador-Palmer, R.; Cibrián Ortiz de Anda, R. Reproducibility of Skin Temperature Response after Cold Stress Test Using the Game Ready System: Preliminary Study. Int. J Environ. Res. Public Health 2021, 18 8295. https://doi.org/10.3390/ ijerph18168295

Academic Editors: Anna Lubkowska and Monika Chudecka

Received: 6 July 2021

Accepted: 3 August 2021

Published: 5 August 2021

Publisher's Note: MDPI stays neutral with regard to jurisdictional claims in published maps and institutional affiliations.

Copyright: (c) 2021 by the authors. Licensee MDPI, Basel, Switzerland. This article is an open access article distributed under the terms and conditions of the Creative Commons Attribution (CC BY) license (https:/ / creativecommons.org/licenses/by/ $4.0 /)$
1 Research Group in Sports Biomechanics (GIBD), Department of Physical Education and Sports, Universitat de València, 46010 Valencia, Spain; ignacio.catala@uv.es (I.C.-V.);

Alberto.encarnacion@uv.es (A.E.-M.)

2 Research Group in Medical Physics (GIFIME), Department of Physiology, Universitat de València, 46010 Valencia, Spain; alexisgandiasoriano@gmail.com (A.G.-S.); Rosario.Salvador@uv.es (R.S.-P.); rosa.m.cibrian@uv.es (R.C.O.d.A.)

3 Department of Physical Education and Sports, Universitat de València, 46010 Valencia, Spain; M.Teresa.Pellicer@uv.es (M.T.P.-C.); J.Luis.Bermejo@uv.es (J.L.B.-R.)

* Correspondence: j.ignacio.priego@uv.es

Abstract: The objective of this preliminary study was to determine the reproducibility of lower limbs skin temperature after cold stress test using the Game Ready system. Skin temperature of fourteen participants was measured before and after cold stress test using the Game Ready system and it was repeated the protocol in four times: at 9:00, at 11:00, at 19:00, and at 9:00 h of the posterior day. To assess skin temperature recovery after cold stress test, a logarithmic equation for each region was calculated, and constant $\left(\beta_{0}\right)$ and slope $\left(\beta_{1}\right)$ coefficients were obtained. Intraclass correlation coefficient (ICC), standard error (SE), and within-subject coefficient of variation (CV) were determined. No differences were observed between measurement times in any of the regions for the logarithmic coefficients $(p>0.38)$. Anterior thigh ( $\beta_{0}$ ICC $0.33-0.47 ; \beta_{1}$ ICC $0.31-0.43$ ) and posterior knee ( $\beta_{0}$ ICC $0.42-0.58 ; \beta_{1}$ ICC $\left.0.28-0.57\right)$ were the regions with the lower ICCs, and the other regions presented values with a fair and good reproducibility (ICC > 0.41). Posterior leg was the region with the better reproducibility ( $\beta_{0}$ ICC $0.68-0.78 ; \beta_{1}$ ICC $0.59-0.74$; SE 3-4\%; within-subject CV 7-12\%). In conclusion, cold stress test using Game Ready system showed a fair and good reproducibility, especially when the posterior leg was the region assessed.

Keywords: infrared thermography; dynamic thermography; cooling; medicine; posterior leg; cryotherapy

\section{Introduction}

The assessment of skin temperature has been used in medicine for diagnosis or evaluation of different pathologies such as those that have an altered peripheral circulation as diabetes or Raynaud's phenomenon, for inflammatory diseases as arthritis, for traumatic injuries, or for malignant diseases such as breast cancer, among others [1-3]. These applications are based on the idea that skin temperature is affected by the inflammation in underlying tissues, by the higher metabolic activity resulted from angiogenesis, by nerve dysfunctions, or by the alteration of skin blood flow [1,3,4]. However, the assessment applications of skin temperature have not been limited to medicine and have also been used in other contexts such as the study of thermoregulation during exercise, the evaluation of the effect of clothing, or the assimilation of the athlete's training load, among others $[4,5]$. However, for some of these applications, baseline skin temperatures could not provide enough information, and Cold Stress Tests (CST) could improve the sensitivity of the prediction and diagnosis $[2,3]$.

CST have been applied for hypertension and diabetic population [6,7] to assess the severity of cold sensitivity [8,9], assess physiological stress the day after a marathon [10], 
or diagnose Raynaud pathology [11]. CST consist of cooling the skin to evaluate the posterior vascularization capacity $[12,13]$. During CST, a higher sympathetic activity results in peripheral vasoconstriction, which facilitates skin temperature reduction [14-16]. After finishing the CST, skin vasodilation increases resulting in a rewarming of skin temperature [14-16]. Although skin temperature rewarming depends mainly on skin blood flow, it can also occur passively from the environment and deeper tissues [13] and is influenced by the duration of the cooling phase [17].

Although there is a high intersubject variability response to CST [18], good reproducibility of skin temperature after CST has been observed by different studies due to a lower within-subject variability $[8,15,19]$. However, this reproducibility is not generalizable to all the body regions [20]. For example, $\mathrm{O}^{\prime}$ Brien [15] observed reproducible finger skin temperatures in the nail bed, but not in the pad. These studies assessed hands and foot, being the most used method the immersion of these extremities in cold water $[8,15,19]$. Therefore, it is necessary to determine the reproducibility for specific regions with new methodologies of CST. In this sense, recently, a system of controlled pressure with cryotherapy (Game Ready ${ }^{\circledR}$, Avanos Medical Inc. Company, Alpharetta, GA, USA) has been used to assess skin temperature of lower limbs after CST [10].

Game Ready ${ }^{\circledR}$ is a system that combines a control unit filled with ice and water that pumps the water constantly to the circumferential wraps (by ducts inserted into the tissue) to apply cold and intermittent pneumatic compression [21]. It has been clinically applied to mitigate pain and inflammation after an injury or during the recovery from different surgeries such as total knee arthroplasty [22], lumbar spinal surgery [23], or hip arthroscopy [24], among others. Although its application for CST is scarce, we decided to investigate its use for CST due to its combination with pressure, allowing the cooling to be more homogeneous over the entire surface. In addition, another advantage would be that the risk of the skin being wet is avoided, as can happen with other CST methods, a critical issue in thermographic analysis [25].

The objective of this preliminary study was to determine the reproducibility of lower limbs skin temperature after CST using the Game Ready system. Considering that this system could homogenize better the conditions than the water immersion methodology, and the regions assessed are less peripherical than hands and foot, which could improve its reproducibility [26], it was hypothesized that skin temperature rewarming after CST would present a good reproducibility.

\section{Materials and Methods}

\subsection{Participants}

Fourteen ( 4 females and 10 males) physically active participants volunteered to participate in the study (mean \pm standard deviation): age $36 \pm 5$ years, height $174 \pm 7 \mathrm{~cm}$, body mass $77.0 \pm 11.6 \mathrm{~kg}$, body fat percentage $21 \pm 8 \%$, muscle mass percentage $76 \pm 10 \%$. Inclusion criteria were to be physically active with a reported training schedule of at least 3 physical activity sessions/week. Exclusion criteria were a history of lower limb injuries within the last month, suffering from heart failure, neurological or musculoskeletal disorders affecting normal locomotion, and taking medication that interferes with stability during running. All participants signed a written consent form, and the University Ethics Committee approved the study. The instructions provided to the participants to control the factors that can affect skin temperature were to avoid exercise, large meals, ointments, and cosmetics in the days of the measurements; to avoid smoking, drinking alcohol, caffeine, or other stimulant beverages from $12 \mathrm{~h}$ before to finishing the measurements; and to avoid physiotherapy treatments, sunbathing and high-intensity physical activity from $24 \mathrm{~h}$ before to finishing the measures. The participants confirmed their compliance with all these instructions. 


\subsection{Design}

To understand the effect of the system or the intra-subject physiological variability, measures were performed in different moments (morning vs. afternoon vs. different day). Therefore, participants were assessed in four times: (1) at 9:00, (2) at 11:00 (to have a measurement in the same day as time 1 and also at morning), (3) at 19:00 (to have a measurement in the same day as time 1 but at afternoon), and (4) at 9:00 of the posterior day (to have a measurement in the same hour as time 1 but in a different day). In the first measurement, body composition variables were obtained using a bioelectrical impedance system (Tanita BC-545N, Tanita Corp., Tokyo, Japan). In all the measurements, participants stood in an upright resting position (men wearing underpants and women in panties) for $10 \mathrm{~min}$ to adapt to the temperature of the room [27]. Once the thermal room adaptation was completed, a thermography image of the preferred lower limb was obtained, CST was performed, and then thermographies were taken again for three minutes $(30,60,120$, and $180 \mathrm{~s}$ ) after finishing CST of the preferred lower limb. These times were taken after observing in a pilot that after removing the wrap and the participant positioned for the image, $30 \mathrm{~s}$ was the minimum time that could be assured to take the first image. Because the skin temperature recovery describes a logarithmic curve, after the minute, the thermal recovery rate is slower, and thermal images can be taken to the minute. CST had a duration of 3 min using an electronic cryotherapy system (Game Ready GRPro 2.1, Avanos Medical Inc. Company, Alpharetta, GA, USA) while the participants were lying supine [10]. The circumferential wrap used was the "full leg boot wrap" model for colling the entire lower limb. The Game Ready system was configured to the lowest temperature (between 0 and $3^{\circ} \mathrm{C}$ ) with moderate pressure for the wrap (intermittent pneumatic compression between 5 and $50 \mathrm{~mm} \mathrm{Hg}$ considering manufacturer information) [10].

Room temperature was controlled with an air conditioning system and environmental conditions were recorded using a thermo-hygrometer (Digital thermo-hygrometer, TFA Dostmann, Germany) with the following values: $19.7 \pm 1.8{ }^{\circ} \mathrm{C}$ room temperature and $38 \pm 3 \%$ of relative humidity.

\subsection{Skin Temperature}

Skin temperature was assessed using an infrared thermography camera (E-60bx, Flir Systems Inc., Wilsonville, OR, USA) with a sensor array size of $320 \times 240$, noise equivalent temperature difference (NETD) $<0.05^{\circ} \mathrm{C}$, instantaneous field of view of $1.36 \mathrm{mrad}$, and measurement uncertainty of $\pm 2{ }^{\circ} \mathrm{C}$. Camera calibration was checked one week before the measurements using a blackbody (BX-500 IR Infrared Calibrator, CEM, Shenzen, China) with a target emissivity of 0.95 , resolution of $0.1^{\circ} \mathrm{C}$, and measurement uncertainty of $\pm 0.8^{\circ} \mathrm{C}$. A Thermographic Imaging in Sports and Exercise Medicine checklist was used to confirm that all the essential aspects of the thermographic protocol were attended [28]. The camera was turned on $10 \mathrm{~min}$ before the measurements and it was positioned $3 \mathrm{~m}$ from the participant. An anti-reflective panel was placed behind the participant to minimize the influence of the radiation reflected [1]. The reflected temperature was measured according to the standard method ISO 18434-1:2008. Measurements were taken in a room absent of sunlight and $5 \mathrm{~m}$ away from any electronic equipment (except the Game Ready system).

The mean temperature of 6 Regions of Interest (ROIs) of the preferred lower limb (Figure 1) with an emissivity of $0.98[28,29]$ was obtained using thermography software (Thermacam Researcher Pro 2.10 software, FLIR, Wilsonville, OR, USA). The same researcher defined ROIs to ensure consistent analysis across the sessions considering body segments. The temperature obtained after the CST $(30,60,120$, and $180 \mathrm{~s}$ after) was subtracted from the one obtained before the cold stress test to assess the skin temperature variation. To assess skin temperature recovery after CST, data were placed in an Excel spreadsheet and a logarithmic equation for each participant, measurement time, and ROI was calculated, and constant $\left(\beta_{0}\right)$ and slope $\left(\beta_{1}\right)$ coefficients were obtained (Figure 2$)$ [10]:

$$
\text { Skin temperature variation }\left({ }^{\circ} \mathrm{C}\right)=\beta_{0}+\beta_{1} \times \ln (\mathrm{T})
$$


where the $\beta_{0}$ and $\beta_{1}$ are the constant and slope coefficients of the equation, respectively; $\ln$ is the natural logarithm; $\mathrm{T}$ is the time lasted after the cold stress in seconds; and skin temperature variation is the difference between the skin temperature at $\mathrm{T}$ respect with pre-cooling moment.

Anterior view

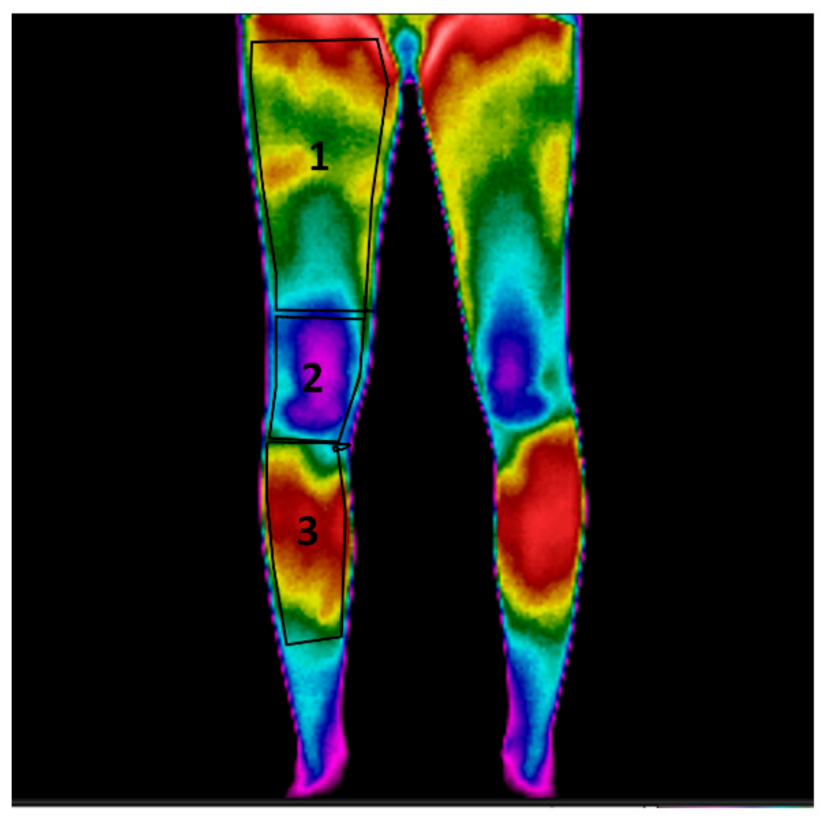

Posterior view

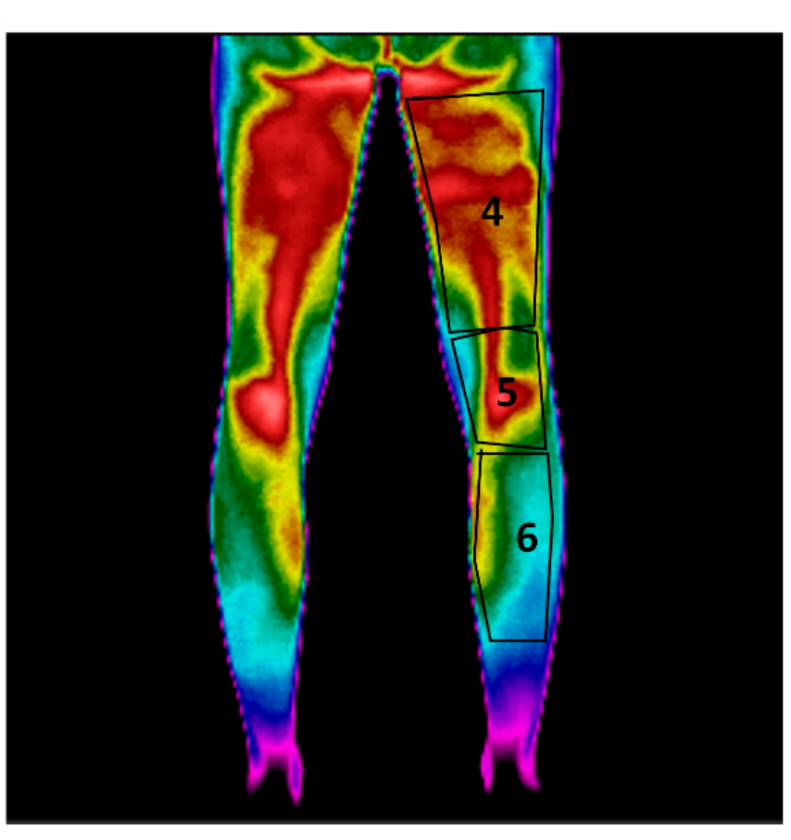

$35^{\circ} \mathrm{C}$

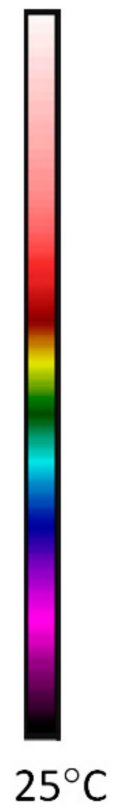

Figure 1. Regions of interest assessed in the preferred lower limb: (1) anterior thigh, (2) knee, (3) anterior leg, (4) posterior thigh, (5) posterior knee, and (6) posterior leg.

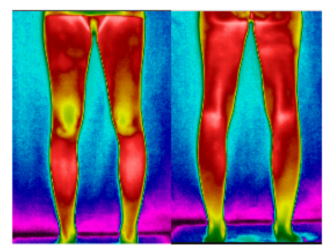

Pre cooling

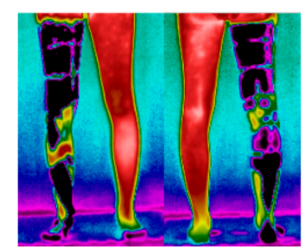

$30 \mathrm{~s}$ after cooling

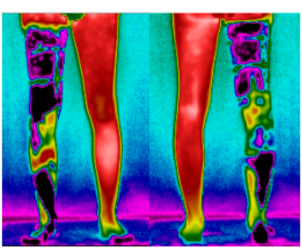

$60 \mathrm{~s}$ after cooling

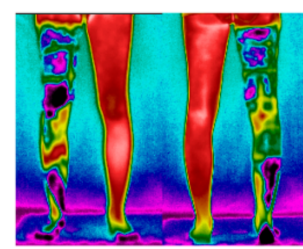

$120 \mathrm{~s}$ after cooling

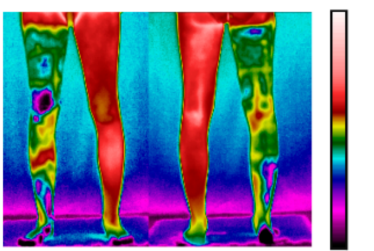

$180 \mathrm{~s}$ after cooling $20^{\circ} \mathrm{C}$

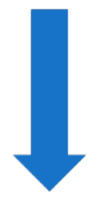

For each region of interest, skin temperature variations were calculated, and logarithmic equation was obtained

Posterior leg

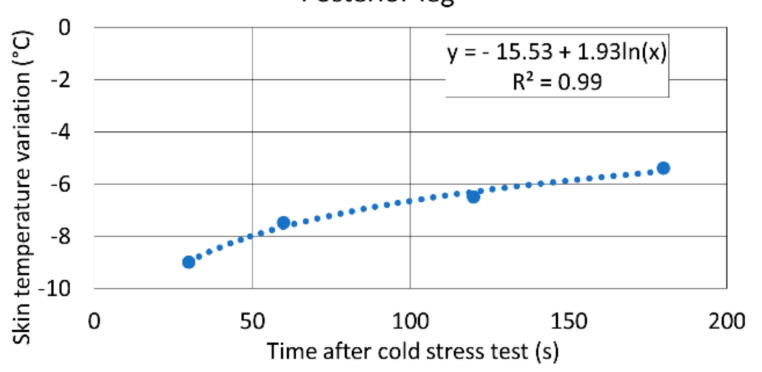

Logarithmic coefficients were obtained:

Skin temperature variation $\left({ }^{\circ} \mathrm{C}\right)=\beta_{0}+\beta_{1} \times \ln ($ time (s))

$$
\begin{aligned}
& \beta_{0}=-15.53 \\
& \beta_{1}=1.93
\end{aligned}
$$

Figure 2. Schematic representation of the process to obtain the logarithmic coefficients to assess cold stress test. 


\subsection{Statistical Analysis}

Statistical analysis was performed using RStudio (version 1.2.5033). The normality of the logarithmic coefficients was confirmed using the Shapiro-Wilk test $(p>0.05)$. Then, for each ROI, repeated-measures analysis of variance with Bonferroni post hoc test were applied with a within-subject factor (measurement time: 9:00 vs. 11:00 vs. 19:00 vs. 9:00 of the posterior day). Significance level was set at $p<0.05$. The intraclass correlation coefficient (ICC), based on a single rater-measurement, absolute-agreement, and 2-way random-effects model, was calculated at each ROI, between different measurement times comparisons: 1-between measurements in the same morning (9:00-11:00), 2-between the measurement at morning and at afternoon (9:00-19:00), 3-between the measurement at morning and $24 \mathrm{~h}$ post (9:00-9:00 day 2 ), and 4-between all measurement times. ICC values were classified as excellent reproducibility (1.00 to 0.75$)$, good reproducibility $(0.74$ to 0.60$)$, fair reproducibility ( 0.59 to 0.40 ), and poor reproducibility (0.39 to 0.00 ) [30]. Standard error (SE) was provided as a measure of uncertainty. Finally, within-subject and between-subject coefficient of variation $(\mathrm{CV})$ was calculated [31].

\section{Results}

Figure 3 shows the skin temperature data used for the calculation of the logarithmic equations. The $\mathrm{R}^{2}$ of the logarithmic equations obtained for each participant demonstrated their good adjustment: anterior thigh $0.95 \pm 0.05$, knee $0.94 \pm 0.06$, anterior leg $0.97 \pm 0.03$, posterior thigh $0.97 \pm 0.04$, posterior knee $0.96 \pm 0.05$, and posterior leg $0.98 \pm 0.02$. Figure 4 shows the logarithmic equations values obtained. No differences were observed between measurement times in any of the ROIs for the $\beta_{0}$ (anterior thigh $p=0.89$, knee $p=0.80$, anterior leg $p=0.61$, posterior thigh $p=0.68$, posterior knee $p=0.96$, and posterior $\operatorname{leg} p=0.39$ ) and $\beta_{1}$ (anterior thigh $p=0.81$, knee $p=0.93$, anterior leg $p=0.59$, posterior thigh $p=0.61$, posterior knee $p=0.87$, and posterior $\operatorname{leg} p=0.43$ ).

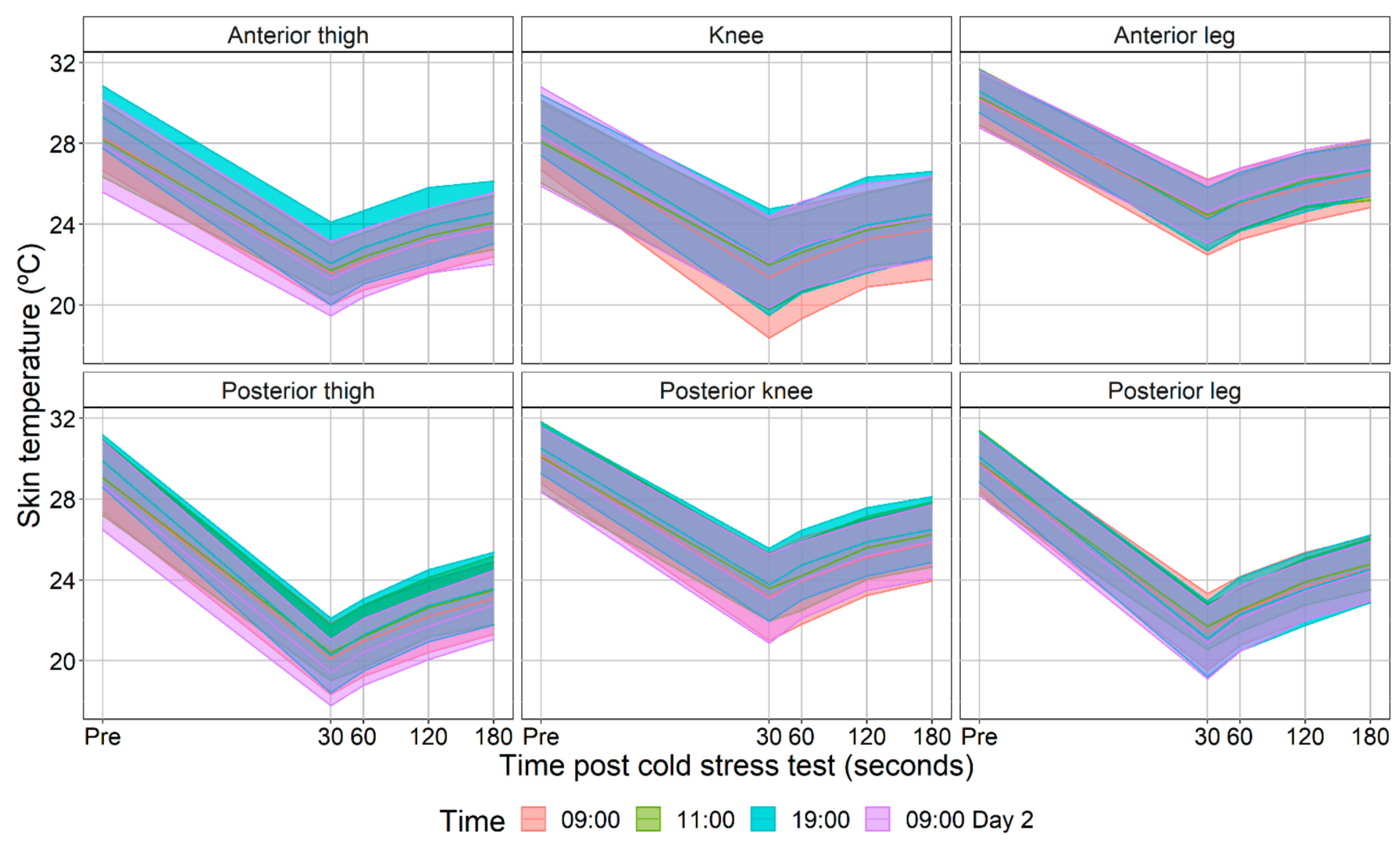

Figure 3. Mean and standard deviation of the evolution of skin temperature before (Pre) and 30, 60, 120, and $180 \mathrm{~s}$ after cold stress test at each measurement time. 

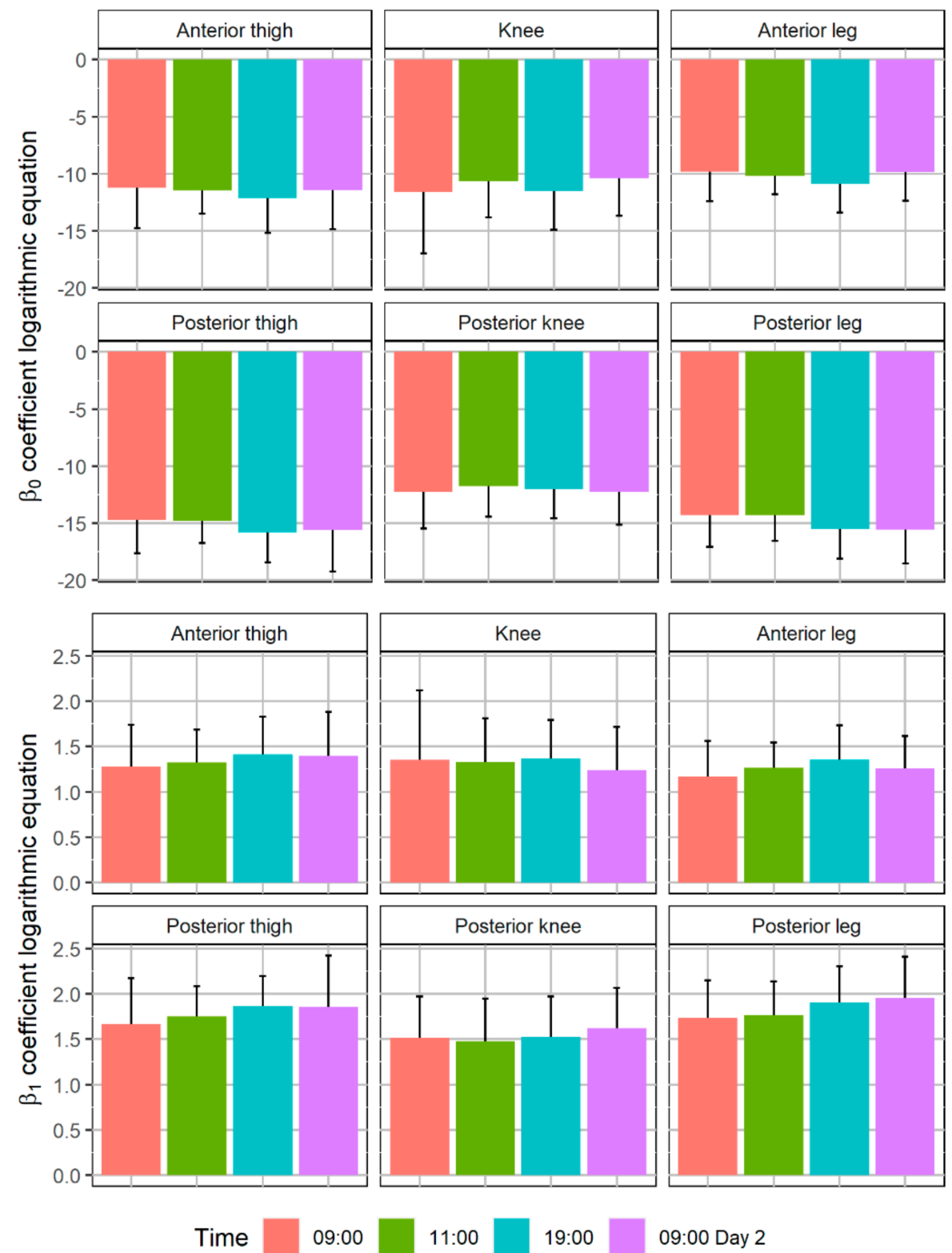

Figure 4. Mean and standard deviation of the coefficients of the logarithmic equations obtained with the cold stress test: Skin temperature variation $\left({ }^{\circ} \mathrm{C}\right)=\beta_{0}+\beta_{1} \times \ln (\mathrm{T})$, where $\beta_{0}$ and $\beta_{1}$ are the constant and slope coefficients of the equation, respectively; $\ln$ is the natural logarithm; $\mathrm{T}$ is the time lasted after the cold stress in seconds; and skin temperature variation is the difference between the skin temperature at $\mathrm{T}$ respect with pre-cooling moment. No differences were observed between measurement times in each region of interest $(p>0.05)$.

Table 1 shows the ICC, SE, and CV values obtained. Generally, comparing the reproducibility obtained between the different ROIs, the ROIs with the lower ICC were the anterior thigh with values between poor and fair reproducibility and ( $\beta_{0}$ ICC $0.33-0.47$; $\beta_{1}$ ICC $\left.0.31-0.43\right)$ and the posterior knee with fair reproducibility ( $\beta_{0}$ ICC $0.42-0.58 ; \beta_{1}$ ICC $0.28-0.57$ ). Posterior thigh presented between fair and good reproducibility $\left(\beta_{0}\right.$ ICC $0.53-0.69 ; \beta_{1}$ ICC $\left.0.38-0.64\right)$, and knee and anterior leg between fair and excellent reproducibility ( $\beta_{0}$ ICC $0.49-0.73$; $\beta_{1}$ ICC $0.42-0.77$ ). Posterior leg was the region with the better reproducibility ( $\beta_{0}$ ICC $0.68-0.78 ; \beta_{1}$ ICC $0.59-0.74$ ). Comparing the different measurement times at each ROI, knee, anterior leg, and posterior thigh presented the highest reproducibility in the comparison between 9:00 and the measurement performed after $24 \mathrm{~h}$ ( $\beta_{0}$ ICC $0.69-0.73 ; \beta_{1}$ ICC $0.64-0.77$ ). The SE of $\beta_{0}$, presented values between 0.3 and 0.8 with a 
mean value of 0.5 , and the SE of $\beta_{1}$ between 0.05 and 0.12 with a mean value of 0.08 . The percentage of the SE respect the mean value of the $\beta_{0}$ coefficient of each ROI was anterior thigh $5 \%$, knee $7 \%$, anterior leg $4 \%$, posterior thigh $3 \%$, posterior knee $4 \%$, posterior leg $3 \%$, and for all the ROIs $4 \%$. The percentage of the SE respect the mean value of the $\beta_{1}$ coefficient of each ROI was: anterior thigh $6 \%$, knee $8 \%$, anterior leg $5 \%$, posterior thigh $5 \%$, posterior knee $5 \%$, posterior leg $4 \%$, and for all the ROIs $5 \%$. Generally, $\beta_{1}$ presented lower reproducibility than $\beta_{0}$, showing also higher SE (4\% vs. 5\%) and within-subject CV ( $\beta_{0}$ CV 7-20\%; $\beta_{1}$ CV 9-27\%). The between-subject CV was higher than the within-subject CV (16-47\% vs. 7-27\%). Finally, the ROIs that presented the lowest within-subject CV was posterior leg (7-12\%), and the ROIs with the highest values were the knee (17-27\%) and the anterior thigh (15-25\%).

Table 1. Intraclass correlation coefficients (IC), standard error (SE), and within-subject and between-subject coefficient of variation $(\mathrm{CV})$ of the measurement times comparisons, considering the coefficients of the logarithmic equations obtained with the cold stress test: Skin temperature variation $\left({ }^{\circ} \mathrm{C}\right)=\beta_{0}+\beta_{1} \times \ln$ (time after the cold stress test (s)).

\begin{tabular}{|c|c|c|c|c|c|c|c|c|c|c|c|c|c|c|c|c|}
\hline & \multicolumn{4}{|c|}{ ICC } & \multicolumn{4}{|c|}{$\mathrm{SE}$} & \multicolumn{4}{|c|}{ Within-Subject CV (\%) } & \multicolumn{4}{|c|}{ Between-Subject CV (\%) } \\
\hline & $\begin{array}{l}9: 00- \\
11: 00\end{array}$ & $\begin{array}{l}9: 00- \\
19: 00\end{array}$ & $\begin{array}{c}9: 00- \\
9: 00 \\
\text { Day } 2\end{array}$ & $\begin{array}{c}\text { All } \\
\text { Mo- } \\
\text { ments }\end{array}$ & $\begin{array}{l}9: 00- \\
11: 00\end{array}$ & $\begin{array}{l}9: 00- \\
19: 00\end{array}$ & $\begin{array}{c}9: 00- \\
9: 00 \\
\text { Day } 2\end{array}$ & $\begin{array}{c}\text { All } \\
\text { Mo- } \\
\text { ments }\end{array}$ & $\begin{array}{l}9: 00- \\
11: 00\end{array}$ & $\begin{array}{l}9: 00- \\
19: 00\end{array}$ & $\begin{array}{c}9: 00- \\
9: 00 \\
\text { Day } 2\end{array}$ & $\begin{array}{c}\text { All } \\
\text { Mo- } \\
\text { ments }\end{array}$ & $\begin{array}{l}9: 00- \\
11: 00\end{array}$ & $\begin{array}{l}\text { 9:00- } \\
19: 00\end{array}$ & $\begin{array}{c}9: 00- \\
9: 00 \\
\text { Day } 2\end{array}$ & $\begin{array}{c}\text { All } \\
\text { Mo- } \\
\text { ments }\end{array}$ \\
\hline & & & & & & & & $\beta_{0}$ & & & & & & & & \\
\hline $\begin{array}{l}\text { Anterior } \\
\text { thigh }\end{array}$ & 0.44 & 0.46 & 0.33 & 0.47 & 0.5 & 0.6 & 0.6 & 0.4 & 15 & 19 & 17 & 18 & 25 & 28 & 31 & 26 \\
\hline Knee & 0.59 & 0.64 & 0.71 & 0.63 & 0.8 & 0.8 & 0.8 & 0.5 & 19 & 20 & 17 & 20 & 38 & 38 & 39 & 34 \\
\hline $\begin{array}{l}\text { Anterior } \\
\text { leg }\end{array}$ & 0.49 & 0.64 & 0.73 & 0.54 & 0.4 & 0.5 & 0.5 & 0.3 & 12 & 12 & 11 & 15 & 21 & 25 & 26 & 23 \\
\hline $\begin{array}{l}\text { Posterior } \\
\text { thigh }\end{array}$ & 0.63 & 0.53 & 0.69 & 0.59 & 0.5 & 0.5 & 0.6 & 0.4 & 9 & 12 & 10 & 12 & 16 & 18 & 21 & 18 \\
\hline $\begin{array}{l}\text { Posterior } \\
\text { knee }\end{array}$ & 0.58 & 0.40 & 0.42 & 0.43 & 0.6 & 0.5 & 0.6 & 0.4 & 15 & 16 & 15 & 17 & 25 & 24 & 25 & 24 \\
\hline $\begin{array}{l}\text { Posterior } \\
\text { leg }\end{array}$ & 0.73 & 0.78 & 0.69 & 0.68 & 0.5 & 0.5 & 0.5 & 0.4 & 7 & 8 & 9 & 10 & 18 & 18 & 19 & 18 \\
\hline & & & & & & & & $\beta_{1}$ & & & & & & & & \\
\hline $\begin{array}{l}\text { Anterior } \\
\text { thigh }\end{array}$ & 0.41 & 0.31 & 0.36 & 0.43 & 0.08 & 0.08 & 0.09 & 0.06 & 18 & 25 & 22 & 23 & 32 & 33 & 36 & 32 \\
\hline Knee & 0.52 & 0.60 & 0.77 & 0.60 & 0.12 & 0.11 & 0.12 & 0.07 & 27 & 24 & 17 & 24 & 46 & 44 & 47 & 41 \\
\hline $\begin{array}{l}\text { Anterior } \\
\text { leg }\end{array}$ & 0.42 & 0.61 & 0.68 & 0.55 & 0.06 & 0.07 & 0.07 & 0.05 & 18 & 16 & 16 & 18 & 28 & 31 & 31 & 28 \\
\hline $\begin{array}{l}\text { Posterior } \\
\text { thigh }\end{array}$ & 0.53 & 0.38 & 0.64 & 0.58 & 0.08 & 0.08 & 0.10 & 0.06 & 14 & 15 & 16 & 15 & 25 & 24 & 31 & 25 \\
\hline $\begin{array}{l}\text { Posterior } \\
\text { knee }\end{array}$ & 0.57 & 0.28 & 0.39 & 0.33 & 0.09 & 0.08 & 0.08 & 0.06 & 19 & 21 & 19 & 23 & 31 & 30 & 29 & 30 \\
\hline $\begin{array}{l}\text { Posterior } \\
\text { leg }\end{array}$ & 0.59 & 0.74 & 0.69 & 0.69 & 0.07 & 0.08 & 0.08 & 0.05 & 12 & 9 & 11 & 12 & 23 & 22 & 23 & 22 \\
\hline
\end{tabular}

\section{Discussion}

The objective of this preliminary study was to determine the reproducibility of lower limbs skin temperature after CST using the Game Ready system. Therefore, participants were measured in four different measurement times: 9:00, 11:00, 19:00, and 9:00 of the posterior day. Coefficients of the logarithmic equation that describe skin temperature recovery after CST were obtained. The main results were that (1) no differences were observed between measurement times in any of the ROIs for the coefficients of logarithmic equation; (2) anterior thigh and posterior knee were the ROIs with the lower ICC with a poor and fair reproducibility, and the rest of the ROIs generally presented values with a fair and good reproducibility; and (3) posterior leg was the region with the better reproducibility and lower uncertainty.

Although a reproducibility between fair and good was obtained for most of the ROIs, anterior thigh and posterior knee presented lower values than the others, which would be something important to consider for future studies. Zaproudina et al. [26] suggested that the reproducibility of skin temperature between different days could be affected by the technical characteristics of the infrared thermography camera, but also by the variability of participants' skin blood flow. Regarding the anterior thigh, although evaluators tried to position the Game Ready system to cover up to the crotch, it might not fit perfectly for some participants, resulting in lower reproducibility. In this sense, in a previous study, the authors did not analyze anterior and posterior thigh ROIs because the Game Ready system did not cover in all cases with the same proportion of the region surface [10]. However, note 
that this lower reproducibility was not observed in the posterior thigh. Another explanation that could be added to the previous one is the contact of the wrap sheath with the lower limb. Although the Game Ready system was configured with medium compression to homogenize its contact with the skin, the posterior regions were also supported on the table by the supine position, which could increase the pressure and improve its contact. All these explanations are attributable to the ROI with the better reproducibility and lower uncertainty, the posterior leg, which was covered completely by the Game Ready system, and where the pressure could be positively affecting. To validate this hypothesis, a future study could analyze the reproducibility of the system using different compression levels and different postures (supine vs. prone). In the posterior knee case, the lower reproducibility of this region may be due to variability in blood flow, as the temperature of the popliteal region is mainly due to the volume of blood circulating through the popliteal artery that branches to the anterior tibial artery, the posterior tibial artery and the peroneal artery [32].

Within-subject CV is the statistical parameter used for most of previous studies and allow to compare reproducibility results. Considering the region of the posterior leg, which obtained the best results for all the parameters assessed (IC, SE, and CV), the within-subject $\mathrm{CV}$ of the logarithmic coefficients had values of $7-12 \%$. These results are in agreement with previous studies that suggested good reproducibility of their CST assessed $[8,15,33]$. These studies presented within-subject $\mathrm{CV}$, during hands and foot cold water immersion, between 8 and 10\% for finger skin temperature [33], between 3 and $11 \%$ of absolute values of skin temperature post immersion [8], between 9 and $12 \%$ for nail bed region [15], and $17-21 \%$ for pad region [15].

A better reproducibility was observed in the comparison between 9:00 and the measurement performed after $24 \mathrm{~h}$ in some of the ROIs (knee, anterior leg, and posterior thigh). This result could be evidencing the effect on the reproducibility of the circadian cycle and increased daily activity with respect to the first measurement. The circadian rhythm was suggested as an important influence factor on skin temperature [34,35], due to its incremental effect on blood flow extremities during the day [36]. In this sense, higher skin temperatures $\left(\sim 1^{\circ} \mathrm{C}\right)$ were observed at the afternoon than at the morning in thigh and legs [35]. Therefore, this should be an aspect to take into account in future research, carrying out the evaluations of the different study conditions at the same time of the day.

$\beta_{1}$ presented lower reproducibility than $\beta_{0}$, also showing higher SE and within-subject $\mathrm{CV}$. $\beta_{0}$ could be associate with the capacity of the Game Ready system to cold down skin temperature and the peripheral vasoconstriction state of the person assessed. If a person has a state of more significant peripheral vasoconstriction, it will facilitate this reduction in temperature $[6,10,37]$. On the other hand, $\beta_{1}$ is related to the rewarming speed and, therefore, peripheral vasodilation capacity $[6,38]$. For this reason, it is logical that $\beta_{0}$ has a higher reproducibility and lower uncertainty as it depends to a greater extent on the cooling system, while $\beta_{1}$ depends mainly on the physiological variability of the participant.

The important advantage of CST has been evidenced by different pathologies and applications such as breast cancer [39], hyperthyroidism [40], hypertension [7], diabetes [6], cold sensitivity [9], Raynaud pathology [11], or physiological stress the day after a marathon [10]. Most of these applications are based on hands and water immersion, and the assessment of full lower limbs is less assessed due to its methodological difficulties. The use of systems of cryotherapy combined with intermittent pneumatic compression to the wrap such as the one used in the present study facilitate this type of analysis, as they are fast, logistically comfortable, and do not wet the skin, which would be a complication for temperature measurement using infrared thermography [25]. The results of the present study suggest the applicability of this type of CST, although if it is carried out with the same method used, the results in the posterior leg will be more sensitive, and less in the rest of the regions due to its lower reproducibility, higher uncertainty, and more within-subject variability. This is in agreement with a previous study that showed that the posterior leg was the only region in which the coefficients of logarithmic equation showed differences $24 \mathrm{~h}$ after running a 
marathon [10]. Finally, another practical application result was the higher between-subject variability compared with the within-subject variability. This suggests that, whenever possible, crossover experimental designs should be performed rather than independent group comparison.

This investigation was considered preliminary due to the sample size, only one type of system configuration was assessed in terms of temperature, pressure, and cold application time, and because the results suggest that the effect of other postures during cooling should be investigated. The main limitation of this preliminary study was that the lack of skin blood flow assessment that could help to interpretate if variability was due to CST methodology or due to the participant's physiology. Moreover, although instructions were provided to the participants to avoid confounding factors, we cannot be sure that some participants did not follow any of the instructions and therefore affect reproducibility results. The Game Ready system can be used with different wrap models to cool specific regions, so future studies need to evaluate reproducibility in other body regions. Moreover, a future study would monitor wrap temperature continuously using contact sensors to assess the system's reproducibility.

\section{Conclusions}

This preliminary investigation suggests that CST using the Game Ready system showed a good reproducibility, especially when the posterior leg was the region assessed. Therefore, its application can be recommended when it is necessary to evaluate the skin temperature of the lower limbs after CST. However, anterior thigh and posterior knee presented lower reproducibility, and these ROIs should be considered with caution when future studies will assess it.

Author Contributions: Conceptualization, J.I.P.-Q., R.S.-P. and R.C.O.d.A.; methodology, J.I.P.-Q. and A.G.-S.; formal analysis, J.I.P.-Q.; investigation, J.I.P.-Q., A.G.-S., M.T.P.-C., I.C.-V. and J.L.B.-R.; resources, J.I.P.-Q. and J.L.B.-R.; data curation, J.I.P.-Q., A.G.-S., M.T.P.-C., I.C.-V. and J.L.B.-R.; writing — original draft preparation, J.I.P.-Q.; writing — review and editing, all authors; visualization, J.I.P.-Q.; supervision, J.I.P.-Q., A.E.-M., R.S.-P. and R.C.O.d.A.; project administration, J.I.P.-Q.; funding acquisition, J.I.P.-Q., M.T.P.-C. and A.E.-M. All authors have read and agreed to the published version of the manuscript.

Funding: This study was funded by "Conselleria de Innovación, Universidades, Ciencia y Sociedad Digital de la Generalitat Valenciana" (Proyectos Emergentes GV/2020/050). The contribution of Catalá-Vilaplana was funded with a doctoral fellowship by "Ministerio de Ciencia, Innovación y Universidades de España" (FPU19/04462).

Institutional Review Board Statement: The study was conducted according to the guidelines of the Declaration of Helsinki and approved by the Institutional Ethics Committee of Universitat de València (protocol code H1540285051003 and date of approval 8 November 2018).

Informed Consent Statement: Informed consent was obtained from all subjects involved in the study.

Data Availability Statement: The datasets generated and analyzed during the current study are available from the corresponding authors on reasonable request.

Acknowledgments: We would like to thank to the participants for their voluntary participation in this study.

Conflicts of Interest: The authors declare no conflict of interest.

\section{References}

1. Hildebrandt, C.; Raschner, C.; Ammer, K. An Overview of Recent Application of Medical Infrared Thermography in Sports Medicine in Austria. Sensors 2010, 10, 4700-4715. [CrossRef]

2. Lahiri, B.B.; Bagavathiappan, S.; Jayakumar, T.; Philip, J. Medical Applications of Infrared Thermography: A Review. Infrared Phys. Technol. 2012, 55, 221-235. [CrossRef]

3. Ring, E.F.J; Ammer, K. Infrared Thermal Imaging in Medicine. Physiol. Meas. 2012, 33, R33. [CrossRef] 
4. Fernández-Cuevas, I.; Lastras, J.A.; Galindo, V.E.; Carmona, P.G. Infrared thermography for the detection of injury in sports medicine. In Application of Infrared Thermography in Sports Science; Priego Quesada, J.I., Ed.; Biological and Medical Physics, Biomedical Engineering; Springer International Publishing: Cham, Switzerland, 2017; pp. 81-109, ISBN 978-3-319-47409-0.

5. Priego Quesada, J.I.; Cibrián Ortiz de Anda, R.M.; Pérez-Soriano, P.; Salvador Palmer, R. Introduction: Historical perspective of infrared thermography and its application in sport science. In Application of Infrared Thermography in Sports Science; Springer International Publishing: Cham, Switzerland, 2017; pp. 1-23, ISBN 978-3-319-47410-6.

6. Zeng, S.; Chen, Q.; Wang, X.; Hong, K.; Li, J.; Li, P.; Cheng, X.; Su, H. Longer Rewarming Time in Finger Cooling Test in Association with HbA1c Level in Diabetics. Microvasc. Res. 2016, 107, 72-75. [CrossRef]

7. Greaney, J.L.; Kenney, W.L.; Alexander, L.M. Neurovascular Mechanisms Underlying Augmented Cold-Induced Reflex Cutaneous Vasoconstriction in Human Hypertension. J. Physiol. 2017, 595, 1687-1698. [CrossRef] [PubMed]

8. House, C.M.; Taylor, R.J.; Oakley, E.H.N. Repeatability of a Cold Stress Test to Assess Cold Sensitization. Occup. Med. 2015, 65, 578-584. [CrossRef] [PubMed]

9. Eglin, C.M.; Costello, J.T.; Bailey, S.J.; Gilchrist, M.; Massey, H.; Shepherd, A.I. Effects of Dietary Nitrate Supplementation on the Response to Extremity Cooling and Endothelial Function in Individuals with Cold Sensitivity. A Double Blind, Placebo Controlled, Crossover, Randomised Control Trial. Nitric Oxide 2017, 70, 76-85. [CrossRef] [PubMed]

10. Priego-Quesada, J.I.; Pérez-Guarner, A.; Gandia-Soriano, A.; Oficial-Casado, F.; Galindo, C.; de Anda, R.M.C.O.; Piñeiro-Ramos, J.D.; Sánchez-Illana, Á.; Kuligowski, J.; Barbosa, M.A.G.; et al. Effect of a Marathon on Skin Temperature Response After a Cold-Stress Test and Its Relationship With Perceptive, Performance, and Oxidative-Stress Biomarkers. Int. J. Sports Physiol. Perform. 2020, 1, 1-9. [CrossRef]

11. Horikoshi, M.; Inokuma, S.; Kijima, Y.; Kobuna, M.; Miura, Y.; Okada, R.; Kobayashi, S. Thermal Disparity between Fingers after Cold-Water Immersion of Hands: A Useful Indicator of Disturbed Peripheral Circulation in Raynaud Phenomenon Patients. Intern. Med. 2016, 55, 461-466. [CrossRef]

12. Zaproudina, N.; Lipponen, J.A.; Eskelinen, P.; Tarvainen, M.P.; Karjalainen, P.A.; Närhi, M. Measurements of Skin Temperature Responses to Cold Exposure of Foot and Face in Healthy Individuals: Variability and Influencing Factors. Clin. Physiol. Funct. Imaging 2011, 31, 307-314. [CrossRef] [PubMed]

13. Davey, M.; Eglin, C.; House, J.; Tipton, M. The Contribution of Blood Flow to the Skin Temperature Responses during a Cold Sensitivity Test. Eur. J. Appl. Physiol. 2013, 113, 2411-2417. [CrossRef] [PubMed]

14. Sawasaki, N.; Iwase, S.; Mano, T. Effect of Skin Sympathetic Response to Local or Systemic Cold Exposure on Thermoregulatory Functions in Humans. Auton. Neurosci. 2001, 87, 274-281. [CrossRef]

15. O'Brien, C. Reproducibility of the Cold-Induced Vasodilation Response in the Human Finger. J. Appl. Physiol. 2005, 98, 1334-1340. [CrossRef]

16. Lahiri, B.B.; Bagavathiappan, S.; Nishanthi, K.; Mohanalakshmi, K.; Veni, L.; Saumya Yacin, S.M.; Philip, J. Infrared Thermography Based Studies on the Effect of Age on Localized Cold Stress Induced Thermoregulation in Human. Infrared Phys. Technol. 2016, 76 , 592-602. [CrossRef]

17. Keramidas, M.E.; Kölegård, R.; Mekjavic, I.B.; Eiken, O. Acute Effects of Normobaric Hypoxia on Hand-Temperature Responses during and after Local Cold Stress. High Alt. Med. Biol. 2014, 15, 183-191. [CrossRef] [PubMed]

18. Leijon-Sundqvist, K.; Tegner, Y.; Juntti, U.; Karp, K.; Lehto, N. Hand Skin Temperature-Are There Warm and Cold Rewarming Patterns after Cold Stress Test. Thermol. Int. 2016, 26, 81-87.

19. Faes, T.J.C.; Wagemans, M.F.M.; Cillekens, J.M.; Scheffer, G.-J.; Karemaker, J.M.; Bertelsmann, F.W. The Validity and Reproducibility of the Skin Vasomotor Test-Studies in Normal Subjects, after Spinal Anaesthesia, and in Diabetes Mellitus. Clin. Auton. Res. 1993, 3, 319-324. [CrossRef]

20. Norrbrand, L.; Kölegard, R.; Keramidas, M.E.; Mekjavic, I.B.; Eiken, O. No Association between Hand and Foot Temperature Responses during Local Cold Stress and Rewarming. Eur. J. Appl. Physiol. 2017, 117, 1141-1153. [CrossRef] [PubMed]

21. GRPro ${ }^{\circledR} 2.1$ Cold Therapy Unit I Cryotherapy Unit for Athlete \& Patient Recovery. Available online: https://gameready.com/grpro-cold-therapy-unit/ (accessed on 27 July 2021).

22. Su, E.P.; Perna, M.; Boettner, F.; Mayman, D.J.; Gerlinger, T.; Barsoum, W.; Randolph, J.; Lee, G. A Prospective, Multi-Center, Randomised Trial to Evaluate the Efficacy of a Cryopneumatic Device on Total Knee Arthroplasty Recovery. J. Bone Joint Surg. 2012, 94, 153-156. [CrossRef]

23. Nabıyev, V.N.; Ayhan, S.; Adhıkarı, P.; Cetın, E.; Palaoglu, S.; Acaroglu, R.E. Cryo-Compression Therapy After Elective Spinal Surgery for Pain Management: A Cross-Sectional Study With Historical Control. Neurospine 2018, 15, 348-352. [CrossRef]

24. Klaber, I.; Greeff, E.; O’Donnell, J. Compressive Cryotherapy Is Superior to Cryotherapy Alone in Reducing Pain after Hip Arthroscopy. J. Hip Preserv. Surg. 2019, 6, 364-369. [CrossRef]

25. Priego Quesada, J.I.; Kunzler, M.R.; Carpes, F.P. Methodological aspects of infrared thermography in human assessment. In Application of Infrared Thermography in Sports Science; Springer International Publishing: Cham, Switzerland, 2017; pp. 49-79, ISBN 978-3-319-47410-6.

26. Zaproudina, N.; Varmavuo, V.; Airaksinen, O.; Närhi, M. Reproducibility of Infrared Thermography Measurements in Healthy Individuals. Physiol. Meas. 2008, 29, 515. [CrossRef] [PubMed] 
27. Marins, J.C.B.; Moreira, D.G.; Cano, S.P.; Quintana, M.S.; Soares, D.D.; de Andrade Fernandes, A.; da Silva, F.S.; Costa, C.M.A.; dos Santos Amorim, P.R. Time Required to Stabilize Thermographic Images at Rest. Infrared Phys. Technol. 2014, 65, 30-35. [CrossRef]

28. Moreira, D.G.; Costello, J.T.; Brito, C.J.; Adamczyk, J.G.; Ammer, K.; Bach, A.J.E.; Costa, C.M.A.; Eglin, C.; Fernandes, A.A.; Fernández-Cuevas, I.; et al. Thermographic Imaging in Sports and Exercise Medicine: A Delphi Study and Consensus Statement on the Measurement of Human Skin Temperature. J. Therm. Biol. 2017, 69, 155-162. [CrossRef]

29. Steketee, J. Spectral Emissivity of Skin and Pericardium. Phys. Med. Biol. 1973, 18, 686. [CrossRef] [PubMed]

30. Cicchetti, D.V.; Sparrow, S.A. Developing Criteria for Establishing Interrater Reliability of Specific Items: Applications to Assessment of Adaptive Behavior. Am. J. Ment. Defic. 1981, 86, 127-137.

31. Shechtman, O. The coefficient of variation as an index of measurement reliability. In Methods of Clinical Epidemiology; Doi, S.A.R., Williams, G.M., Eds.; Springer Series on Epidemiology and Public Health; Springer: Berlin/Heidelberg, Germany, 2013; pp. 39-49, ISBN 978-3-642-37131-8.

32. Kropman, R.H.J.; Kiela, G.; Moll, F.L.; de Vries, J.-P.P.M. Variations in Anatomy of the Popliteal Artery and Its Side Branches. Vasc. Endovasc. Surg. 2011, 45, 536-540. [CrossRef]

33. Daanen, H. Central and Peripheral Control of Finger Blood Flow in the Cold. Ph.D. Thesis, Free University, Amsterdam, The Netherlands, 1997.

34. Costa, C.M.A.; Sillero-Quintana, M.; Piñonosa Cano, S.; Moreira, D.G.; Brito, C.J.; Fernandes, A.A.; Pussieldi, G.A.; Marins, J.C.B. Daily Oscillations of Skin Temperature in Military Personnel Using Thermography. BMJ Mil. Health 2016, 162, 335-342. [CrossRef]

35. Marins, J.C.B.; Formenti, D.; Costa, C.M.A.; de Andrade Fernandes, A.; Sillero-Quintana, M. Circadian and Gender Differences in Skin Temperature in Militaries by Thermography. Infrared Phys. Technol. 2015, 71, 322-328. [CrossRef]

36. Smolander, J.; Härmä, M.; Lindgvist, A.; Kolari, P.; Laitinen, L.A. Circadian Variation in Peripheral Blood Flow in Relation to Core Temperature at Rest. Europ. J. Appl. Physiol. 1993, 67, 192-196. [CrossRef]

37. Leijon-Sundqvist, K.; Lehto, N.; Juntti, U.; Karp, K.; Andersson, S.; Tegner, Y. Thermal Response after Cold-Water Provocation of Hands in Healthy Young Men. Thermol. Int. 2015, 25, 48-53.

38. Burkes, S.A.; Patel, M.; Adams, D.M.; Hammill, A.M.; Eaton, K.P.; Randall Wickett, R.; Visscher, M.O. Infantile Hemangioma Status by Dynamic Infrared Thermography: A Preliminary Study. Int. J. Dermatol. 2016, 55, e522-e532. [CrossRef] [PubMed]

39. Amri, A.; Pulko, S.H.; Wilkinson, A.J. Potentialities of Steady-State and Transient Thermography in Breast Tumour Depth Detection: A Numerical Study. Comput. Methods Programs Biomed. 2016, 123, 68-80. [CrossRef] [PubMed]

40. Jin, C.; He, Z.Z.; Yang, Y.; Liu, J. MRI-Based Three-Dimensional Thermal Physiological Characterization of Thyroid Gland of Human Body. Med. Eng. Phys. 2014, 36, 16-25. [CrossRef] [PubMed] 